\title{
El turismo como instrumento de política ambiental en el Santuario de la Mariposa Monarca EI Rosario
}

\section{Tourism as an environmental policy instrument in El Rosario Monarch Butterfly Sanctuary}

\author{
Susana Esquivel-Ríos* \\ Graciela Cruz-Jiménez* \\ Cecilia Cadena-Inostroza** \\ Lilia Zizumbo-VILlarReaL ${ }^{*}$
}

\begin{abstract}
The environmental policy in Mexico was implemented as a mechanism to slow down the deterioration of natural areas; such is the case of the monarch butterfly biosphere reserve, in which its efficacy is questioned because of the permanent deterioration, reflected on the loss of woods, mortality of the butterflies and depletion of aquifers, stressed by massive tourism. This is the consequence of the difficulties in the implementation and participating actors. The analysis was carried out from the approach of the Networks of Public Policy. The main conclusion is that there is limited inter-institutional coordination, which makes communication and agreement between actors difficult.
\end{abstract}

Keywords: environmental policy, monarch butterfy, tourism, policy networks.

\section{Resumen}

La política ambiental en México se implementó como un mecanismo para frenar el deterioro en áreas naturales como la Reserva de la Biosfera de la Mariposa Monarca, sin embargo, se cuestiona su eficacia debido al continuo deterioro, la pérdida de bosques, la mortandad de la mariposa, y la disminución de mantos freáticos; todo esto acentuado por el turismo masivo. Esto es consecuencia de las dificultades de implementación de la política ambiental y de los actores que participan en ella. El análisis se realizó bajo el enfoque de Redes de Política Pública. La principal conclusión es que existe una limitada coordinación interinstitucional y esto dificulta la comunicación y acuerdo entre actores.

Palabras claves: Política ambiental, mariposa monarca, turismo, redes de política pública.

*Universidad Autónoma del Estado de México. Correo-e: susanaer_re83@yahoo.com, gracicj@ hotmail.com,1zv04@yahoo.com

**El Colegio Mexiquense, A.c. Correo-e: ccadena@cmq.edu.mx 


\section{Introducción $^{1}$}

La tardía e insuficiente atención de la problemática ambiental en México provocó la degradación y la pérdida de ecosistemas, riesgos en la salud humana y la vulnerabilidad de la población, lo que hasta la fecha incide en el bienestar social y en el potencial desarrollo del país. Si bien, en el pasado tal situación no estuvo en el primer plano del debate nacional pese a su influencia en materia económica, social, natural y política, en la década de los años setenta del siglo xx, el continuo deterioro ambiental obligó a considerarla un problema público que exigió el establecimiento de políticas, si no para solucionarlo, al menos para reducirlo.

El sentido público, tal y como lo establece Aguilar (1996), implica un nuevo proceso de decisión, gestión, colaboración e interlocución entre los distintos actores que realizan parte de las acciones para atenderlo: el gobierno en sus distintos ámbitos, las organizaciones no gubernamentales, y el sector privado y social. En tal sentido, el gobierno mexicano creó una política ambiental enfocada en promover la sustentabilidad, la viabilidad de los ecosistemas y su biodiversidad, así como en equilibrar la relación entre la sociedad y la naturaleza a partir de modelos apropiados de gestión, política, participación, normatividad y eficiencia de los marcos legales e institucionales (FARN, 2009).

Como parte de esta política ambiental, el gobierno federal promovió no sólo la creación de diferentes áreas naturales protegidas y de instrumentos legales y de organizaciones públicas enfocadas en la conservación y protección de los recursos naturales; también promovió nuevas actividades -entre ellas el turismo- encaminadas al fomento, la conservación y la protección de los recursos naturales que, a su vez, generarán beneficios económicos y sociales a las poblaciones locales.

Otras de las acciones implementadas en todas las áreas naturales por el gobierno federal se refirieron al establecimiento de comités técnicos e instituciones de fideicomisos, inversión privada, promoción de estímulos fiscales y económicos, y elaboración de sus planes de manejo (Brenner, 2009). Sin embargo, pese a la implementación de medidas, como parte de la política ambiental para la conservación y protección del recurso, estos espacios continúan presentando altos índices de contaminación y degradación ambiental.

${ }^{1}$ Este documento se deriva de la investigación "El turismo y la política ambiental en el Santuario de Mariposa Monarca El Rosario a la luz de las redes de política pública" del Programa de maestría en estudios turísticos de la Facultad de Turismo y Gastronomía de la Universidad Autónoma del Estado de México. En él se expone la implementación de la política ambiental en México y su aplicación en la Reserva de la Biosfera de la Mariposa Monarca, especialmente en el Santuario El Rosario, poniendo el acento en la actuación de los actores públicos, sociales y privados. 
Entre los esfuerzos por legitimar la política ambiental fue creada la Reserva de la Biosfera de la Mariposa Monarca (RBMM), ubicada en los estados de México y Michoacán. La importancia de ésta radica en que, durante los meses de octubre a febrero, alberga a la mariposa monarca para su hibernación, fenómeno migratorio que abarca Estados Unidos, Canadá y México; este desplazamiento fue declarado en 2008 por la unesco como Patrimonio de la Humanidad. Su relevancia también está dada por ser un área de captación de agua de lluvia que alimenta a numerosos cuerpos que abastecen a centros urbanos y localidades de la región, y por albergar a una vasta diversidad de especies ${ }^{2}$ (Programa de la RBMM, 2001 citado en Esquivel-Ríos et al., 2011).

En ambas entidades, a partir de 1986 fueron establecidas áreas denominadas santuarios de la mariposa monarca (Programa de la RBMM, 2001). En el Estado de México están distribuidas en los municipios de Temascalcingo, San Felipe del Progreso, Donato Guerra y Villa de Allende; en Michoacán, en las demarcaciones de Contepec, Senguio, Angangueo, Zitácuaro, Aporo y Ocampo (Esquivel-Ríos et al., 2011); en este último está ubicado el Santuario El Rosario, uno de los que registra mayor afluencia turística pero también problemas como tala clandestina, inadecuado aprovechamiento forestal, y pérdida de flora y fauna, aunque en él participen, una amplia gama de instituciones para su conservación, aprovechamiento y desarrollo de la actividad turística.

En tal sentido, el presente artículo analiza las relaciones entre los actores que interactúan en El Rosario, en el marco de una red que, en forma abstracta, representa la realidad; el propósito es conocer los resultados derivados de tales relaciones, de la implementación de la política ambiental y de las acciones turísticas puestas en marcha en el Santuario El Rosario durante la década del 2000 a 2010, cuando ese ejido fue decretado como Santuario.

La contribución de este artículo está orientada en dos sentidos: por una parte, ampliar la visión desde la cual ha sido abordado el turismo, ya que tradicionalmente se ha hecho énfasis en su faceta económica y de servicios, dejando de lado otras aristas, como la política. En concordancia con ello, también aspira a evidenciar, a partir de los supuestos teóricos del enfoque de redes de política pública aplicados a un caso local, cómo las relaciones resultantes entre los actores que interactúan en torno a una

${ }^{2}$ Como parte de su biodiversidad están registradas 493 especies de plantas vasculares, así como 49 de hongos, entre otras. Asimismo alberga cinco tipos de vegetación: bosque de oyamel que se caracteriza por la predominancia de Abies religiosa y constituye el hábitat característico de la mariposa monarca; bosque de pino y de oyamel, bosque de pino, bosque de encino y bosque de cedro. Además cuenta con una gran diversidad de fauna silvestre representada por 198 especies de vertebrados, de los cuales cuatro son anfibios y seis reptiles; 132 de aves y 56 de mamíferos, destacando el coyote y el venado (Programa de la RBMm, 2001). 
política, en este caso, la ambiental, son las que configuran en último término sus resultados. Dicho enfoque fue el suministro teórico de la investigación que da soporte a este artículo, el cual recién empieza a permear en México, mientras que en Europa y Estados Unidos ha sido utilizado desde varias décadas atrás.

Por otra parte, se analiza el papel del turismo en un contexto de concienciación y conservación del ambiente (entendido como hombrenaturaleza). Asimismo, se exponen las formas de colaboración de la comunidad asentada en el Santuario con personajes de otros sectores, de forma tal que los resultados permiten no sólo conocer la realidad por la que atraviesa El Rosario en torno a la política ambiental, sino también el papel que ha desempeñado y desempeńa en él la actividad turística. La presente investigación propone, como objetivo general, el análisis de las acciones de los actores públicos, sociales y privados que participaron en torno a la política pública ambiental y a las labores turísticas en el Santuario El Rosario para determinar su nivel de participación e interlocución en la conservación y aprovechamiento de los recursos naturales en lo general, y particularmente para el turismo. En la hipótesis planteada se cuestiona la forma en que se han coordinado los actores públicos, sociales y privados en el Santuario de la Mariposa Monarca El Rosario, ya que se considera que esto ha provocado duplicidad, inacción y omisión de funciones en torno a la política ambiental, generando así presión y deterioro de sus recursos naturales; además ha impedido condiciones propicias para el turismo sustentable.

En apego a estos planteamientos, en el primer apartado del presente documento se presenta el marco bajo el cual fue implementada la política ambiental mexicana, de la que se deriva como una de sus acciones más importantes el decreto de Reservas de la Biosfera. Por tanto, se hace énfasis en que las características de estas áreas naturales protegidas sirven como contexto para entender la situación tanto natural como social que prevalece en el Santuario de la Reserva de la Biosfera de la Mariposa Monarca y de esta forma tener mayores elementos de análisis.

En la segunda parte del artículo se abordan los postulados de la actividad turística bajo una perspectiva de sustentabilidad, con el propósito de vincularlos con los principios normativos de la política ambiental y establecer qué tan compatibles o disímiles son respecto a la situación real que presenta el Santuario.

El tercer apartado está centrado en el enfoque de redes de política pública que posibilita el estudio de las relaciones, el intercambio de recursos e información entre los actores; además, las reglas, rutinas informales y los vínculos organizacionales que limitan y estructuran los procesos y el estilo de interacción entre los integrantes de la red. 
En la cuarta parte se brinda una panorámica sobre el Santuario de la Mariposa Monarca El Rosario en el marco de la RBMM, como contexto del análisis efectuado en esa área natural. Sus resultados se plasman en la parte final, donde se enfatiza la forma en que intervinieron los actores públicos, sociales y privados, su grado de participación, inacción e incluso duplicidad de funciones en la conservación de los recursos naturales cuyo deterioro continúa pese a la existencia del referido ordenamiento legal para evitarlo. También se explican las relaciones que éstos establecieron entre sí en función de los recursos de distinto tipo que han puesto en juego en el marco de dicha política (específicamente del turismo), así como el grado de dependencia o cooperación entre ellos.

\section{Reservas de la biosfera en el contexto de la política ambiental}

Durante los años setenta del siglo pasado se expandió en el ámbito internacional la preocupación por el deterioro de los recursos naturales, resultado de impactos ambientales agudos (incluida la pérdida de especies silvestres y ecosistemas), la disminución de mantos freáticos, y la erosión de los suelos derivados de procesos ancestrales como conflictos agrarios, fuertes presiones demográficas e industriales, proyectos agropecuarios, explotación y deterioro de vastas áreas de bosques, conflictos por agua o por dominio de territorio, demanda de madera para combustible y para la industria de la construcción, falta de interés de comunidades por conservar sus recursos, y el turismo masivo.

La pérdida acelerada del patrimonio natural se consideró entonces un problema público, entendido como aquella cuestión o demanda que el gobierno ha seleccionado como objeto de acción sobre el que hay que poner atención (Rosas, 2008). No obstante, Aguilar (1996) advierte que este tipo de problemas no sólo se caracteriza por afectar a un grupo considerable de personas, sino también por la complejidad y escasez de recursos, aunados a la diversidad de perspectivas y a las condiciones externas que lo rodean. Por tanto, debe ser resuelto mediante el diseño e implementación de políticas públicas basadas en el uso de los recursos intelectuales, legales, económicos, políticos y administrativos disponibles.

En diferentes foros internacionales se destacó la necesidad de un mayor compromiso político de los Estados-Nación para tomar medidas que contrarrestaran el deterioro ambiental progresivo y conservaran la biodiversidad (Brenner, 2009). En concordancia con esta panorámica, entre los años ochenta y noventa fue implementada en México una política pública de conservación del ambiente que permitiera, si no solucionar el problema, al menos mitigarlo. 
Como parte de las principales acciones se dispuso la creación de Áreas Naturales Protegidas (ANP) en todo el país, que fungieran como soporte de conservación, uso sustentable y distribución equitativa de los recursos, además que posibilitaran el manejo y control de la relación entre la naturaleza y las poblaciones humanas. En suma, el propósito era controlar y restringir las actividades humanas que pusieran en peligro la biodiversidad. Aunque de manera explícita no hace referencia al turismo, este es un factor que, dependiendo de su conducción, puede contribuir al deterioro o a la conservación de los recursos naturales.

La creación de ANP implicó, en términos formales, mayor participación, trabajo, transparencia, compromiso y corresponsabilidad de los sectores vinculados en esta tarea: la búsqueda de un verdadero sentido público. En el caso mexicano y hasta la fecha, el gobierno federal, los diferentes estados y la mayoría de municipios han ordenado disposiciones en la materia.

Una de las principales acciones derivadas de la creación de ANP fue el establecimiento de Reservas de la Biosfera (RB), categoría otorgada por la UNESCO en el marco del programa MaB (Hombre y Biosfera), la cual se constituye como un importante instrumento para la conservación de la diversidad biológica y el uso sostenible de sus componentes. Actualmente existen 507 RB en todo el mundo distribuidas en 102 países, 42 para el caso de México, formando una red mundial (RENPA, 2011).

Se establece que estas reservas deben ser representativas de una región biogeográfica significativa y contener paisajes, ecosistemas y especies o variedades de animales y plantas que requieran ser conservados. A la vez, deben cumplir tres funciones básicas: conservación, desarrollo y apoyo logístico. Para ello requieren tener un sistema de zonificación con una o más zonas núcleos, una zona tampón y otra de transición flexible (o área de cooperación); la primera de ellas debe estar protegida legalmente y asegurar una protección a largo plazo del paisaje, de los ecosistemas y de sus especies, y ser suficientemente grande para garantizar los objetivos de la conservación.

Asimismo, puede haber varias zonas núcleo en una sola Reserva de Biosfera; la zona tampón o de amortiguamiento debe poseer límites bien definidos que rodeen la zona núcleo y permitir el desarrollo de actividades organizadas (investigación experimental, tierras de cultivo, bosques o pesca, educación, turismo y recreación) que no sean un obstáculo para los objetivos de conservación de la zona núcleo, sino para asegurar su protección. Por último, en la zona de transición o zona de cooperación exterior se pueden desarrollar diversas actividades agrícolas, asentamientos humanos y otras formas de aprovechamiento (RENPA, 2011). 
En el caso de México, en 1986 se decretó la Reserva de la Biosfera de la Mariposa Monarca, con un área de resguardo de 56 mil hectáreas ubicadas en el Estado de México y Michoacán; posteriormente fue declarada Reserva de la Biosfera en el 2000, y Patrimonio de la Humanidad por la unesco en el 2008 (El Sol de Morelia, 2008).

Para operar la política ambiental, el territorio de la RBMM fue segmentado en tres zonas núcleo: Cerro Altamirano, Cerro Pelón y el corredor Chincua-Campanario-Chivati-Huacal que incluye al santuario El Rosario en el estado de Michoacán (DOF, 2000); estas zonas núcleo albergan santuarios que promueven la protección a largo plazo del paisaje, de los ecosistemas y de la mariposa monarca. Las únicas actividades permitidas en ellas son investigación y seguimiento, así como usos extractivos locales y recreación. Sin embargo, aunque las características de protección y conservación de estos santuarios se respaldan por un decreto emitido por el gobierno federal, ninguno de ellos cuenta con un programa de manejo y de conservación ambiental, lo cual evidencia que en la mayoría de los casos los santuarios sólo se encuentran protegidos en el discurso y no en la práctica.

El objetivo planteado para esta RBMM prioriza la conservación y protección del medio ambiente. A partir de la creación de la RBMM, la política ambiental procuró hacer sustentable el proceso de desarrollo económico y social de las localidades, velando por el derecho a vivir en un medio libre de contaminación, la protección del ambiente, la preservación de la naturaleza y la conservación del patrimonio ambiental. Este desarrollo sustentable es considerado como un proceso integral que exige a los distintos actores de la sociedad compromisos y responsabilidades en la aplicación del modelo económico, político, ambiental y social, así como en los patrones de consumo que determinan la calidad de vida (Foladori, 2002). Tales aspectos se encuentran estrechamente ligados, al menos en términos teóricos, con los principios del turismo en un marco de sustentabilidad.

La hipótesis planteada cuestiona la forma en la que se han coordinado los actores públicos, sociales y privados en el Santuario de la Mariposa Monarca El Rosario, lo que ha provocado duplicidad, inacción y omisión de funciones en torno a la política ambiental, y al mismo tiempo ha generado presión y deterioro de sus recursos naturales, además de haber impedido condiciones propicias para el turismo sustentable. 


\section{El turismo en Áreas Naturales Protegidas bajo una perspectiva de sustentabilidad}

El turismo puede constituirse como un elemento que apoye los supuestos del desarrollo sustentable; si bien éste tiene amplios alcances, para el caso aquí analizado no necesariamente se cumplen debido a un contexto en el que intervienen diversos actores con intereses no homogéneos, recursos dispares y diferentes vínculos de cooperación en torno a la política ambiental en el Santuario El Rosario.

En tal sentido, en el presente apartado se pretende dar cuenta sobre los supuestos más importantes de este tipo de desarrollo y su relación con el turismo para dimensionar cuáles son las limitantes, pero también las posibilidades de que esta actividad se constituya realmente como una estrategia de la política ambiental por sí misma compleja, ya que integra elementos naturales, económicos, políticos y sociales, todos ellos, dimensiones de la sustentabilidad.

El éxito de la política ambiental depende de una serie de factores que incluye, entre otras acciones, fomentar un intercambio equitativo y uso eficiente de los recursos entre los diversos sectores sociales, reducir la dependencia de los recursos no renovables, descentralizar y diversificar la capacidad productiva. Del mismo modo, se debe establecer un marco jurídico que garantice el respeto a las personas y al ambiente, adoptar y acatar las convenciones internacionales, además de realizar planes municipales y nacionales (Foladori, 2002). A la vez, el desarrollo debe basarse en el uso eficiente, equitativo y ambiental de los recursos naturales, humanos y económicos.

Las ANP, y en caso específico las RB, tienen como objetivos primordiales mejorar la cobertura de la diversidad natural y cultural, la ordenación del territorio y lugares de experimentación del desarrollo sustentable por medio del apoyo, y la participación de las poblaciones locales, así como fomentar la educación, la conciencia pública y la participación. Asimismo, las RB buscan alcanzar el equilibrio deseado entre la actividad humana, el desarrollo y la protección del ambiente mediante una responsabilidad compartida de manera equitativa y bien definida, teniendo presente el impacto ambiental de las distintas actividades y la utilización de los recursos naturales (Brenner y Job, 2012).

En este marco y en concordancia con los anteriores argumentos, el diseño e implementación de proyectos turísticos en áreas naturales se ha calificado formalmente como una actividad sustentable encaminada a la conservación del hábitat. En tal sentido, se espera que estos proyectos sean soportables ecológicamente a largo plazo, viables económicamente y equitativos desde una perspectiva ética y social para las comunidades 
locales. Pese a estos planteamientos, la dinámica propia que prevalece en cada uno de esos espacios se contrapone en ocasiones con el discurso y emergen situaciones particulares como la que se aborda en este acercamiento al referido santuario.

Como elementos que dan soporte a este análisis, se retoman las ideas de Juan y Seva (2005), quien establece que para encaminarse a los propósitos del desarrollo sustentable, respecto a una gestión global de los recursos permitiendo conservar el entorno natural y cultural (incluyendo las áreas protegidas), el turismo debe conocer a profundidad la realidad del espacio socioeconómico sobre el que se quiere actuar, así como las características actuales y potenciales de las comunidades donde se desarrollo la actividad.

Asimismo, se debe procurar una planificación integral que incluya las diferentes variables macroeconómicas, medioambientales, culturales y territoriales que intervienen en el turismo y vincularlas con la gestión de la demanda turística para distribuirla sin reducir el número total de llegadas y adaptar la capacidad de carga a los usos turísticos. La planificación posibilita minimizar el impacto ambiental de estas actividades.

Otras acciones deseables para la práctica responsable del turismo, según Juan y Seva, son adaptar la legislación a las nuevas concepciones medioambientales y hacer que esta normatividad se cumpla; tener en cuenta aspectos como el tratamiento de las aguas residuales, el suministro del agua potable y la recolección de la basura ante el incremento de los visitantes y el tamaño de las poblaciones; y controlar las actuaciones turísticas con mecanismos de vigilancia mediante un plan detallado de protección y un seguimiento de su cumplimiento. El conocimiento y limitaciones por parte de la sociedad son fundamentales para la implantación de actividades ligadas a un desarrollo sustentable; de ahí que la formación de políticas sea una herramienta de primer orden para lograrlo.

Pese a lo anterior, el discurso teórico-normativo sobre el diseño de proyectos turísticos sustentables ha sido cuestionado en diferentes frentes debido a la escasa participación de las comunidades locales, la carencia de información para la toma de decisiones y la ausencia de personal capacitado, así como de recursos y medios para su implementación. En conjunto, estos elementos reflejan una política alejada del discurso oficial y de la realidad. En este sentido, los esfuerzos de la investigación que soporta este documento se enfocaron en el análisis de las relaciones de dependencia e interdependencia entre los actores que han participado en el diseño e implementación de proyectos basados en la política ambiental.

La herramienta teórica que apoyó este proceso fue el enfoque de redes de política pública, que pone acento en estudiar las relaciones entre actores sociales públicos y privados a partir del intercambio de sus recursos 
(de conocimiento, de información, de financiamiento, entre otros), conducidos por acuerdos resultantes de negociaciones, en particular, encaminadas a la conservación y aprovechamiento de los recursos naturales. De esta forma, el presente enfoque permite conocer el papel del turismo, ya sea como una actividad que ha contribuido al deterioro de los recursos o, por el contrario, como factor para cumplir los amplios propósitos expuestos en este apartado.

\section{Las redes de política pública como enfoque analítico del proceso de política ambiental y del turismo}

Si bien en las últimas décadas se ha desdibujado la actuación del sector público ante la intervención de actores sociales y privados que impulsan estrategias que anteriormente eran exclusivas del ente público, éste sigue siendo un elemento importante en la orientación de políticas públicas, entre ellas la ambiental, que se analiza en este documento, que alienta la intervención de diversos actores.

Parte de la función de los gobiernos está enfocada en la atención a problemas de carácter público; sin embargo, tal responsabilidad se ha visto afectada por distintos factores como corrupción, nepotismo y la ineficiencia directiva de las propias administraciones. Si bien la implementación de la democracia en el gobierno permitió avanzar hacia su legitimización, no resolvió el problema de incapacidad para gobernar, por lo que fue necesario descentralizar sus funciones con la finalidad de enfrentar un nuevo escenario que tuviera como prioridad la solución de problemas públicos, dando lugar al surgimiento de políticas públicas, en muchos casos encarando la insuficiencia de recursos para su adecuada gestión.

Las políticas públicas, tal y como lo establece Aguilar (2007), surgieron como un instrumento de conocimiento y gestión útil para reconstruir un gobierno que se encontraba en aprietos. Estas líneas de acción se reconocen como un proceso de aprendizaje colectivo para aumentar la capacidad de resolver problemas, influyendo en la formulación y legitimación de la agenda pública mediante un proceso de comunicación democrática entre sociedad, gobierno y sector privado (Quintero, 2007).

En el caso que nos ocupa, las políticas públicas son una pieza fundamental para la gestión ambiental, ya que su existencia determina el camino a seguir en la conservación, aprovechamiento y adecuada gestión de los recursos naturales. Además, traducidas en programas y acciones, influyen en gran medida en el rumbo de la vida económica, política, administrativa, social, cultural y ambiental de una nación, estado o municipio, y en consecuencia, de sus habitantes. Por su parte, la actividad 
turística cobra nuevas dimensiones según las líneas de acción que la orienten (Cruz, 2008).

Las políticas públicas son dinámicas y no lineales, y son resultado de la interacción entre una gran variedad de actores; es decir, se definen como un conjunto de decisiones y acciones intencionalmente coherentes tomadas por diferentes actores, públicos o no, a fin de resolver de manera puntual problemas políticamente definidos como colectivos. Este conjunto de acciones y decisiones da lugar a actos formales con un grado de obligatoriedad variable, tendientes a modificar las conductas de los grupos sociales que, se supone, originaron el problema colectivo a resolver (gruposobjetivo) en el interés de grupos sociales que padecen los efectos negativos del problema en cuestión (beneficiarios finales) (Subirats, 2008).

Vásquez (2007) propone elaborar un marco teórico para estudiar la problemática ambiental en respuesta a la falta de un concepto común a la participación ciudadana, de trabajo en equipo y de organización dentro de la política pública ambiental. En tal sentido, la complejidad que reviste el análisis de formación e implementación de las políticas en general y, para este caso la ambiental, requiere de un acercamiento teórico que estudie diferentes aristas.

El enfoque de redes de políticas públicas atiende tales particularidades, por lo que en concordancia con el propósito y contribución ya referidos para este artículo, permitió el acercamiento empírico al caso abordado para analizar las relaciones entre los actores participantes en torno a la política ambiental y de esta forma conocer los alcances y limitaciones de dicho ordenamiento.

De acuerdo con Klijn (1998), este enfoque tiene sus raíces teóricas en la ciencia política y la ciencia organizacional; además retoma diversos elementos de la teoría inter-organizacional, tales como una estructura de autoridad no central, un poder con base en la necesidad de recursos, valores en conflicto, y el intercambio y flujo de recursos para la sobrevivencia de los actores que conforman la red. Estas variables apoyaron la investigación empírica en el santuario y forman parte de la propuesta metodológica que le dio soporte.

\section{Desarrollo metodológico}

Para los fines de la investigación que nutre este documento, la red fue definida como una estructura configurada por vínculos más o menos estables que mantienen un determinado número de integrantes públicos y privados y que intercambian recursos materiales e inmateriales. Por tanto, la red alienta una gran cantidad de relaciones definidas por sujeciones mutuas de dependencia (Scharpf, 1978), ya que se dificulta obte- 
ner recursos de cualquier tipo sin la cooperación de otros actores de la red en el proceso de formulación, decisión y ejecución de políticas públicas (Porras, 2001).

Un elemento más que se tomó en cuenta, que por lo general deja de lado otras perspectivas analíticas, fue el no normativo. Las redes de política pública retoman elementos informales para explicar cómo, a pesar de ciertos elementos que en teoría podrían favorecer o afectar determinadas acciones, al final toman un rumbo diferente dependiendo cómo se relacionen los actores a partir del juego político que despliegan y la forma en que éste influye en la conducción de acciones y decisiones, como en este caso las turísticas, y su orientación hacia características sustentables o no (Cruz et al., 2010).

En su conjunto, los anteriores elementos fueron útiles para el acercamiento empírico al estudiar la política ambiental y el turismo dentro del Santuario El Rosario en el marco de la RBMM. Asimismo, permitieron no sólo centrarse en los patrones de relación entre los participantes que la conforman, sino también en sus interdependencias y la forma cómo influyen dentro de la red.

La importancia de dicho enfoque para esta investigación fue una contribución analítica que permitió acercarse a las múltiples y complejas formas a través de las cuales, en la actualidad, se vinculan quienes participan en la formulación, decisión y ejecución de la política ambiental, así como su relación con el turismo en el Santuario El Rosario. El proceso de investigación se orientó hacia un análisis posicional cuyo objetivo fue establecer las propiedades relacionales de los diferentes integrantes respecto al conjunto de la red (Klijn, 1998).

Por lo tanto, el punto de partida del presente análisis fue la identificación de los actores públicos, sociales y privados que han participado en el Santuario. Entre los primeros destacan dependencias federales y estatales; entre los sociales, las organizaciones no gubernamentales y los propios ejidatarios poseedores de la tierra; y en los privados, prestadores de servicios turísticos, todos ellos, alrededor de la política ambiental y de la oferta de servicios al visitante.

Para este análisis se clarificó el papel de cada uno de los integrantes de la red, con el fin de conocer su grado de participación e injerencia sobre otros. Los principios que establece Klijn (1998) para guiar las investigaciones de redes de política pública por medio del análisis posicional son: de prominencia, de equivalencia estructural y de centralidad, siendo este último el que se acercó más a cumplir con el objetivo de estudio en que se basó este artículo, ya que hace referencia al punto de la red en el cual se concentró el mayor número de recursos, funciones y competencias. 
Este fue el referente a partir del cual se ordenaron los participantes de la red: los centrales estuvieron situados en el centro de decisión en materia ambiental y turística en el santuario, participaron cotidianamente en las discusiones y, mediante su relación simbólica, influyeron en la definición de los resultados; los intermediarios que, a pesar de no situarse en el centro de la red, influyeron de forma discontinua por medio de sus alianzas; y por último los periféricos, situados en las zonas más distantes de la red y por lo tanto, raramente consiguieron influir en el centro, por lo que tal marginalidad los alejó del consenso.

La identificación de los participantes determina el nivel y fuerza de envolvimiento en la arena política pública, la cual se pudo definir como un espacio en que efectivamente actúan las redes de actores o los actores individuales (Lowi, 2000); no se trató de un espacio físico, sino simbólico, donde los integrantes de la red lucharon por predominar en ella. Hoy más que nunca este argumento ha mantenido su vigencia tal y como lo refiere Aguilar (1996), respecto a que cada arena tiende a desarrollar su propia estructura política, su proceso político, sus élites y relaciones de grupo. Para esta investigación se partió del supuesto de que el Santuario de la Mariposa Monarca El Rosario no representó en sí mismo una arena, sino que dentro y fuera de él han existido varias arenas donde se libraron, y actualmente continúan librándose, juegos políticos que influyen en la conformación del turismo (en el marco de la política ambiental), lo que continúa incidiendo en la orientación de esta actividad.

El enfoque de redes de política pública se basó en la dependencia de los actores públicos, privados y sociales que han participado en el Santuario El Rosario por medio del intercambio de sus recursos - de conocimiento, de información y financieros-. Este proceso se llevó a cabo mediante acuerdos resultantes de negociaciones previas encaminadas a sustentar los adecuados recursos para su permanencia en la red. Su estructura de poder no fue central, es decir, cada uno de los participantes, en distintos momentos, controló sus propios recursos, de manera que interactuó no sólo para el alcance de sus objetivos, sino también para permanecer dentro de la misma, pues ninguna organización puede generar por sí misma todos sus recursos.

Por otra parte, las interdependencias dentro de una red se generaron por las interacciones entre los participantes que crearon y sustentaron los patrones de relaciones. La interdependencia también implicó cierta ganancia para los participantes. Esto pudo ser el resultado de intereses más o menos articulados en un sector de política específica (Klijn, 1998).

Con base en los supuestos teóricos expuestos, este enfoque posibilitó conocer la forma en que los distintos actores de la red participaron en el proceso de la política ambiental y el turismo; sin embargo, pese a los 
esfuerzos de éstos por implementar medidas para la conservación y protección del santuario, éste continúa presentando altos índices de contaminación y degradación ambiental.

\section{Caracterización del Santuario de la Mariposa Monarca El Rosario}

Como ya fue establecido, en el marco de los esfuerzos por implementar la política ambiental en México fue creada la Reserva de la Biosfera de la Mariposa Monarca; dentro de su territorio se delimitaron ciertas áreas a las cuales se donominó Santuarios de mariposa monarca, los cuales se ubican en los municipios de Temascalcingo, San Felipe del Progreso, Donato Guerra y Villa de Allende, en el Estado de México, y Contepec, Senguio, Angangueo, Aporo, Zitácuaro y Ocampo, en Michoacán.

Estos santuarios han estado sometidos a condiciones diferentes en los órdenes partidista, presupuestal, de aprovechamiento y conservación. Al respecto, la RBMM ha sido una de las ANP más conflictivas en México porque su influencia no se restringió únicamente a sus zonas bajo protección especial, sino que fue extensiva a todas las localidades urbanas y rurales aledañas a los sitios protegidos.

En el 2000 el territorio rural del municipio de Ocampo fue decretado como uno de los santuarios de la RBMM; este santuario conocido como El Rosario limita al norte con los municipios de Aporo y Angangueo, al este con el Estado de México, al sur con Zitácuaro y al oeste con Tuxpan (Servicio Geológico Mexicano, 2000; INEGI, 1981); el clima que prevalece es $\mathrm{C}(\mathrm{w} 2)(\mathrm{w})$ y corresponde a semifrío húmedo con lluvias en verano; la precipitación promedio es de $1000 \mathrm{~mm}$ y la temperatura oscila entre 6.5 y $22^{\circ} \mathrm{C}$ (García, 1981). La frecuencia de heladas al año es de 80 a 100 días (SARH, 1992). El tipo de vegetación que predomina es bosque de oyamel, de pino, de encino, de Juniperus y de Cupressus; así como llanos y vegetación saxícola (Alonso, 1994). La fauna silvestre no es muy abundante debido al impacto que han producido la deforestación y la cacería furtiva; sin embargo, aún se encuentran especies de mamíferos, aves, insectos, reptiles y anfibios (Orduña y Salas et al., 1987; INE, 1987).

El ejido de este santuario se compone de aproximadamente 2,284 habitantes; cuenta con red de agua semipotable entubada que proviene de manantiales cercanos a la región. Las principales actividades económicas son, en orden decreciente, la forestal, la ganadera, el vivero, la agricultura y la acuicultura (Loredo, 2000).

El Rosario posee poco más de cuatro colonias de mariposas monarca que se concentran en el Valle de los Conejos y las Balsitas, cuya temperatura es templada de día y de noche; no obstante, la presencia de mariposa monarca en esos lugares generó una radical transformación en la dinámi- 
ca interna y externa de la localidad debido a la cancelación de los aprovechamientos forestales, los cuales representaban la actividad más significativa para la economía de los ejidatarios, como lo afirman Serrano y Sánchez (2008), quienes lo interpretaron como un despojo de recursos de vida (leña para la energía doméstica y limitación en cuanto al aprovechamiento de la fauna y flora comestibles).

Cabe mencionar que técnicos de dependencias federales limitaron el aprovechamiento del bosque, lo que significó una desvinculación entre los ejidatarios con su ecosistema, ya que anteriormente utilizaban para consumo propio recursos cuyo uso también se restringió con esta medida, lo cual generó resistencias y confrontaciones con las autoridades gubernamentales, pues los ejidatarios consideraron que el decreto era en contra del pueblo, lo que propició que se negaran a trabajar con el gobierno (Serrano y Sánchez, 2008).

Tal situación provocó inconformidad en los habitantes del municipio de Ocampo, por lo que se interpuso un amparo en contra de esa medida, hecho que obligó al gobierno federal a implementar, por medio de la Semarnat, un nuevo decreto en 2007 que permitió desincorporar del santuario los predios de los ejidatarios que ganaron el amparo, restituyendo los permisos de aprovechamiento forestal en la zona núcleo (EsquivelRíos et al., 2011).

Por lo anterior, se respetó el régimen de tenencia social ejidal o comunal de la tierra de El Rosario, lo que ratificó, por derecho, la propiedad de sus habitantes, tanto de territorios como de recursos. Frente a este hecho, el primer problema fue conciliar un interés público enfocado en la preservación de los ecosistemas y de sus recursos ambientales con las necesidades e intereses de aquellos que, por derecho de tenencia, habían estado utilizando los recursos de su territorio mediante actividades como el cultivo, cría de ganado, aprovechamiento forestal y uso tradicional de flora, fauna y del turismo, el cual se ha considerado como una de las actividades más importantes durante el periodo de hibernación de la mariposa (Programa de la RBMM, 2001).

Pese a ello, el enfrentamiento con las autoridades gubernamentales, no ha cesado en El Rosario ya que los ejidatarios han expresado y continúan teniendo un total rechazo a los programas del gobierno estatal y federal, así como de organizaciones no gubernamentales. Sin embargo, con el cierre de las fuentes de empleo en la localidad, la desregulación estatal (producto de la orientación neoliberal de la política rural mexicana) y el mantenimiento de la veda forestal, los ejidatarios se han abierto paulatinamente a la aceptación de la actividad turística que se ha realizado bajo las propias reglas y formas de organización establecidas por el ejido (Serrano y Sánchez, 2008). 
Por lo tanto, los principales problemas de la región se enmarcaron en la necesidad de conservar los recursos naturales (en particular el bosque) y aumentar los ingresos de corto plazo de la producción. Con lo primero, se trató de asegurar la conservación y protección de los sitios de hibernación, el arribo y permanencia de la mariposa monarca durante el invierno y así garantizar el fenómeno migratorio, además de conservar la biodiversidad y la calidad ambiental de la región; con lo segundo, se pretendió mejorar la calidad de vida de la población que hasta la fecha habita en la zona.

En el marco de las actividades alternativas que se plantearon para conservar los recursos naturales y a su vez mejorar la calidad de vida de la población en El Rosario, el turismo desempeñó un papel importante en dos sentidos: fungir como generador de empleos y como contenedor de presión sobre el bosque; no obstante, resalta el hecho de que aun antes de que el área fuera decretada santuario de la mariposa monarca, el arribo del lepidóptero ya atraía año con año a un creciente número de visitantes cuyas demandas en un inicio tuvieron que ser atendidas sin una adecuada infraestructura (Esquivel-Ríos et al., 2011). Tal afluencia fue considerada, en los últimos ańos, como uno de los elementos que amenazaron a los recursos naturales (en general y concretamente a la mariposa) porque la actividad turística se realizó sin servicios óptimos, desorganizadamente, sin una adecuada planeación. En contraparte, el turismo se vislumbró como una alternativa que generó recursos económicos entre los pobladores del santuario pues algunos habían emigrado en busca de empleo.

Los conflictos tras la implementación de la actividad turística en el santuario fueron una respuesta a la carencia de estructuras legales que, en su momento, posibilitaran la participación de los diferentes sectores en la administración y conducción del santuario, aunado a la inexistencia de programas tanto en materia ambiental como turística y, al complejo entramado de actores públicos, privados y sociales que han participado de forma descoordinada e irregular en torno a la política ambiental y al turismo.

Ahora bien, el punto de partida para el siguiente apartado fue la delimitación de los actores públicos, sociales y privados que participaron en el proceso de diseño e implementación de la política ambiental y de la actividad turística en el Santuario del 2000 al 2010 ya que, de acuerdo con el modelo de planeación, cada organización tiene sus propios intereses, dinámicas y valores.

Para este caso, existió una amplia constelación de personajes que se enlazaron sin ninguna cohesión ya que, aunque varios de ellos pertenecieron al sector público e incluso al mismo ámbito de gobierno, en algu- 
nas ocasiones no compartieron intereses. Otro de los problemas de esta complejidad fue la falta de capacidad administrativa para resolver las contrariedades de manera colegiada con otras organizaciones, pues cada una de ellas tuvo procedimientos y rutinas propias; entre más actores participaron en la gestión e implementación de la política ambiental más puntos de decisión existieron, por lo que existieron más demoras en el proceso y, quizás lo más importante, es que en algunos casos quienes participaron en la formación de la política no lo hicieron con la misma fuerza durante su implementación.

\section{Turismo en el Santuario de la Mariposa Monarca como instrumento de política ambiental}

El análisis fue realizado en dos periodos que enmarcaron la trayectoria de la política ambiental y la actividad turística en el Santuario El Rosario durante la década de estudio: el primero corresponde al 2000, cuando se decretó al ejido como parte de la zona núcleo de la Reserva de la Biosfera de la Mariposa Monarca, dándole la categoría de Santuario hasta el 2003, cuando se contó con la participación de una amplia gama de actores con el diseño y creación del Foro Regional de la Mariposa Monarca. El segundo periodo comprendió del 2004 -a partir de la implementación del primer Foro Regional de Mariposa Monarca- al 2010, lapso durante el cual fueron diseñados marcos normativos que permitieron implementar la política ambiental y el turismo (pese a la complejidad de la diversidad de actores públicos, privados y sociales que de manera intermitente han participado en El Rosario).

Los resultados de esta investigación se basaron en una profunda revisión bibliográfica y electrónica sobre los temas de política pública ambiental en México, redes de política pública, RBMm y del santuario El Rosario, entre otros, con la finalidad de identificar aquellas organizaciones que tuvieron una participación relevante entre 2000 y 2010 en la red de política ambiental de la RBMM, principalmente en el Santuario El Rosario. Este proceso se realizó por medio de un mapeo que permitió no sólo identificar los recursos que cada organización posee y aportó a la red, sino también su grado y constancia de participación; de igual manera fueron aplicadas entrevistas a profundidad a las autoridades municipales, prestadores de servicios turísticos y ejidatarios, lo que permitió ampliar y contrastar los resultados obtenidos del mapeo en materia de organización, conservación, rendición de cuentas, control y beneficio de la actividad turística, vínculos con otros santuarios, entre otros elementos.

Con base en lo anterior, se puede decir que las acciones que se enfocaron en promover una eficiente gestión ambiental de los recursos natu- 
rales en El Rosario comenzaron en el 2000, con el decreto que amplió el territorio de la RBмм y convirtió al municipio de Ocampo en santuario. Esto generó situaciones contradictorias, ya que el propósito fue reducir la explotación forestal, regular el arribo del lepidóptero mediante la incorporación de programas que prohibieran la tala inmoderada de árboles e incluso, se pretendió regular la actividad turística -que se desarrollaba de forma desordenada-; no obstante, esta medida generó descontento entre los ejidatarios, pues el régimen de tenencia social de la tierra de $\mathrm{El}$ Rosario es ejidal, lo que convertía a sus habitantes en propietarios por derecho (de territorios y de recursos), por lo que vieron afectadas sus actividades económicas cotidianas y las oportunidades de empleo en aquella zona.

Aunado a lo anterior, el decreto del santuario coincidió con el cierre de las principales fuentes de empleo regional, como la Compañía Minera de Angangueo que, pese a no formar parte del santuario, ofrecía fuentes de empleo para sus habitantes. También fueron cerrados los viveros frutícolas Cariflor y las instalaciones industriales de la Unión de Ejidos Melchor Ocampo, que ofrecían un total 1,170 empleos (DOF, 2000). Fue cuestionada la capacidad directiva del gobierno federal para atender el problema que generó el decreto, ya que, durante esta etapa, el proceso de diseño e implementación de la política ambiental fue centrado únicamente en las capacidades del gobierno, sin la interacción o participación de la comunidad de Ocampo. En tal sentido, los ejidatarios manifestaron que el decreto iba en contra del pueblo, por lo que el ejido se negó a trabajar con el gobierno tal como lo menciona uno de los ejidatarios. Aunque estaban conscientes que no debían talar, en el municipio de Angangueo ya se había cerrado la mina y el bosque, lo cual propició frases como "entonces de qué iban a vivir" (La Voz de Michoacán, 1993: 6).

La falta de visión común entre el gobierno federal y los ejidatarios impidió la implementación de acciones y estrategias inmediatas que dieran respuesta a las necesidades de conservación y empleo. Esto puede atribuirse a la falta de recursos económicos, humanos, de comunicación o incluso de información, lo que dejó en claro que el gobierno fue agente de dirección necesario pero insuficiente, ya que la participación de la comunidad tendría que haber sido decisiva en el diseño e implementación de la política ambiental.

A partir de 2001 se comenzó a contar con la participación de actores públicos y sociales como la Secretaría de Recursos Naturales y Pesca (Semarnap, ahora Semarnat) mediante su órgano descentralizado, la Comisión Nacional de Áreas Naturales Protegidas (Conanp), en conjunto con el gobierno de Michoacán, y el sector académico y científico (aunque no queda claro su nivel de participación), quienes llevaron a cabo el Progra- 
ma de manejo del santuario, ${ }^{3}$ en el que se establecieron las primeras estrategias y acciones de planeación para la administrción de los recursos naturales y operación adecuada del santuario. Esto se realizó por medio de la combinación de tareas de restauración ecológica, protección, investigación, desarrollo sustentable, difusión, educación ambiental, capacitación y recreación para que se permitiera asegurar la conservación del bosque, así como las condiciones ambientales necesarias para la hibernación y reproducción de la mariposa monarca, así como el aseguramiento de su ciclo migratorio.

En apoyo al programa de manejo del santuario, la Semarnat, mediante la Conanp y el Ayuntamiento del municipio de Ocampo, estableció estrategias que incluyeron la creación de un programa de ordenamiento turístico por medio de la adecuada zonificación de áreas con potencial para desarrollar actividades principalmente ecoturísticas, así como la elaboración del Reglamento administrativo del Santuario dirigido a actores públicos, privados y sociales. Esto constituyó un primer esfuerzo por regular actividades en materia recreativa, administrativa, de autoconsumo, aprovechamiento sustentable de los recursos, capacidad de carga, investigación y turística.

Por lo anterior, estas medidas fueron insuficientes puesto que la limitada comunicación interinstitucional a nivel federal, estatal y municipal dificultó el flujo de la información, impidiendo la participación de aquellas organizaciones que contaban con los recursos necesarios para no sólo hacer valer el decreto e implementar dichas estrategias, sino para segmentar los problemas del santuario y resolverlos en conjunto con la comunidad.

En este contexto, fue hasta 2003 que los tres ámbitos de gobierno y la sociedad civil decidieron apoyar las estrategias en materia ambiental planteadas en un inicio, al tiempo que conformaron el Foro Regional Mariposa Monarca. Cabe destacar que en la primera fase de su creación participó una amplia gama de dependencias gubernamentales. ${ }^{4}$ Pese a ello, no en todos los casos su actuación fue central, sino también peri-

${ }^{3}$ El Programa de manejo del santuario fue elaborado con fundamento en lo dispuesto en la Ley Orgánica de la Administración Pública Federal, la Ley General de Equilibrio Ecológico y Protección al Medio Ambiente (Legeepa), así como el reglamento interior de la Semarnat, entre otros ordenamientos legales (DOF, 2000).

${ }^{4}$ Las dependencias federales que intervinieron en la conformación del foro fueron: la Comisión Nacional del Agua (Conagua), Semarnat y su órgano descentralizado la Conanp, la Secretaría de Turismo (Sectur), además de la Secretaría de Agricultura, Ganadería, Desarrollo Rural, Pesca y Alimentación (Sagarpa), la Secretaría de Desarrollo Social (Sedesol), la Secretaría de Comunicaciones y Transportes (sct), así como la Procuraduría Federal de Protección al Ambiente (Profepa), el Instituto Nacional de Ecología (INE), la Comisión Nacional Forestal (Conafor), el Instituto Nacional de Antropología e Historia (INAH), el Sistema Nacional para el Desarrollo Integral de la Familia (DIF); asimismo participaron el gobierno del estado de Michoacán y su Secretaría de Urbanismo y Medio Ambiente (suma), la Secretaría de Desarrollo Agropecuario (Sedagro), la Secretaría de Desarrollo Económico (Sedeco), el Consejo Estatal de Ecología, la Coordinación de Planeación para el Desa- 
férica, intermediaria o incluso nula, pues en un inicio no existía una reglamentación clara y explícita sobre la competencia de los diferentes sectores en asuntos de materia ambiental y turística en El Rosario, por lo que se presentaron intervenciones descoordinadas, resultado de los diversos puntos de decisión que limitaron el éxito de la política.

La Semarnat ocupó una posición central y, mediante su titular, Alberto Cárdenas Jiménez, sugirió que el foro y sus acciones se basaran en tres rubros: económico (incluyendo alternativas para las comunidades), sociocultural y ambiental. Asimismo, estableció que por medio de esa dependencia se gestionaran apoyos ante otras instancias gubernamentales -posición intermediaria- que podrían canalizar recursos propios en apoyo al foro y a la instrumentación de las actividades prioritarias identificadas, a la vez de recomendar enfocarse en la reforestación, los suelos, la prevención de incendios y los servicios ambientales.

Por otra parte, la Conanp asumió el liderazgo en la organización y coordinación del foro y lideró la conformación del grupo operativo que tendría como una de sus funciones la supervisión de acciones realizadas en el Santuario El Rosario. Este grupo quedó conformado, en su momento, por representantes de la Conanp, del Gobierno del Estado de Michoacán, del Ayuntamiento de Ocampo, de la Sectur, Sagarpa delegación Michoacán y del Instituto de Geografía-unam y World Wildlife Fund (WWF).

Al mismo tiempo, el representante de la Comisión Forestal del Estado de Michoacán sugirió incluir en el foro a Bosque Modelo Monarca -en su calidad de ONG- y a sus asociados en Canadá, el cual era parte de la Red Internacional de Bosques Modelo. Con esto se pretendía que en el Santuario se mejorara el nivel de vida de sus pobladores y se fortaleciera la economía de la región, coadyuvando a la conservación del hábitat de la mariposa, así como a la proyección a nivel internacional del santuario (Rendón et al., 2005). No obstante, el secretario de Desarrollo Agropecuario de Michoacán consideró que la propuesta de la Conanp en torno al foro tenía un enfoque demasiado ambiental y que debería dársele más importancia a la participación de las comunidades locales y al gobierno municipal de Ocampo para que acogieran como suya la iniciativa, en coincidencia con el representante de Alternare A.c., quien, a su vez, destacó la necesidad de hacer partícipes a las comunidades para asegurar el éxito no sólo del foro, sino de la propia política ambiental.

En resumen, esta etapa se caracterizó por una amplia participación del sector público, ya que de él emanó y se creó la estructura para llevar a

rrollo (Cplade), la Comisión de Pesca, la Comisión de Ecología del Congreso y la Procuraduría Agraria (Rendón et al., 2005). 
cabo la implementación de la política ambiental en El Rosario. No obstante, no todos los participantes tuvieron relación con la política en cuestión, lo cual reflejó hasta este momento cierta inmadurez interinstitucional, dado que sólo algunas instituciones tuvieron un papel central al concentrar todo el poder, mientras que otras participaron en un ambiente de incertidumbre al no encontrar vínculo entre sus objetivos y la problemática relacionada con el santuario.

Del mismo modo, fue escasa la intervención de actores sociales e incluso nula la del sector privado (figura I). En su conjunto los anteriores hechos limitaron en cierta forma el desarrollo de la política ambiental, pues quienes se percibieron excluidos bloquearon la propia política mediante la continua tala de árboles y el turismo masivo. El panorama en años subsiguientes mejoró en cuanto fue constante y central la intervención de actores públicos, privados y sociales; asimismo, se diseñaron marcos normativos que dieron lugar a la realización de acciones benéficas para la política ambiental en el Santuario El Rosario.

Para interpretar los resultados correspondientes a los dos periodos de la investigación fue construida para cada uno de ellos (mediante el programa de software Ucinet) una red basada en el análisis posicional de centralidad propuesto por Klijn (1998), el cual hace referencia al punto de la red donde se concentró el mayor número de recursos, funciones y competencias de los actores participantes.

Ese fue el referente a partir del cual se ordenaron los personajes de la red: los centrales estuvieron situados en el centro de decisión en materia ambiental y turística en el santuario, participaron cotidianamente en las discusiones y, mediante su relación simbólica, influyeron en la definición de los resultados: los intermediarios, quienes, a pesar de no situarse en el centro de la red, influyeron en ella de forma discontinua por medio de sus alianzas; por último, los periféricos están situados en las zonas más distantes de la red y, por lo tanto, raramente consiguieron influir en el centro, por lo que tal marginalidad los alejó del consenso.

En el marco de la segunda etapa de la política ambiental en el Santuario El Rosario, el grupo operativo' conformado por actores públicos y sociales centrales ${ }^{5}$ llevó a cabo en 2004 el primer Foro Regional de la Mariposa Monarca. No obstante, pese a la colaboración interinstitucional en materia ambiental y turística, el foro no logró contar con el mismo

\footnotetext{
${ }^{5}$ La organización del foro estuvo a cargo de los siguientes actores públicos federales: Semarnat, Sagarpa, Conanp, Conafor, así como la Procuraduría Federal de Protección al Ambiente (Profepa) y el Instituto de Geografía de la Universidad Nacional Autónoma de México (UnAm). Las instituciones de carácter estatal incluyeron a la Coordinación de Relaciones Interinstitucionales (CRI), la Secretaría de Urbanismo y Medio Ambiente (suma), la Secretaría de Turismo (Sectur) y la Comisión Forestal (Cofom). En materia municipal participó el Ayuntamiento de Ocampo. La sociedad civil estuvo representada por WwF.
} 


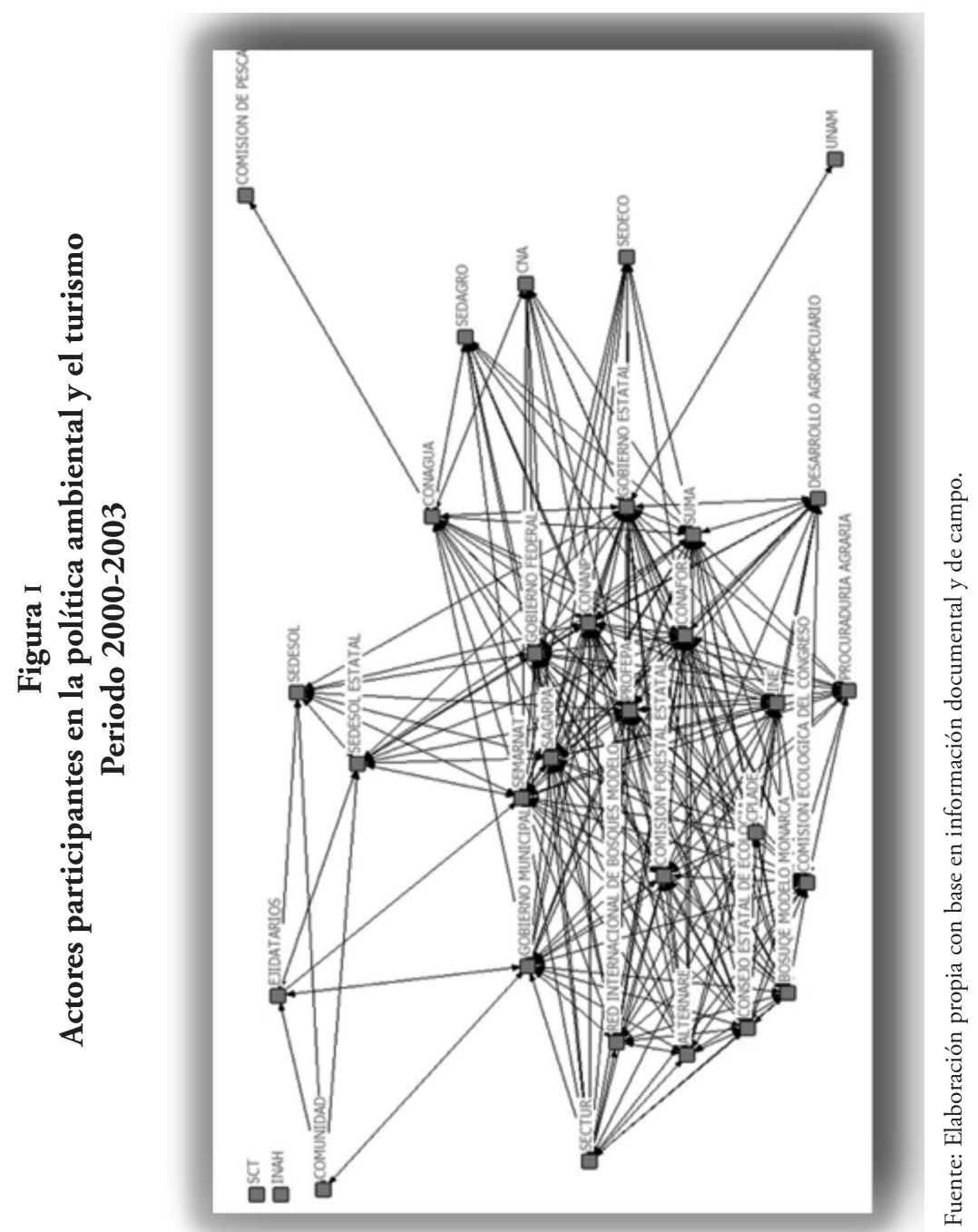


número de integrantes que un año antes se habían comprometido a trabajar en él. Esto se atribuye, entre otros factores, a intervenciones discontinuas, falta de interés, de presupuesto o simplemente porque decidieron apoyar otros proyectos ambientales. Aunado a lo anterior, nuevamente se limitó la participación de los ejidatarios del santuario debido a la escasa difusión oficial sobre el evento y a la carencia de recursos económicos para trasladarse a la ciudad sede del foro, lo cual se constató durante la fase empírica de la investigación.

A pesar de lo anterior, durante la segunda etapa de análisis de la política ambiental se evidenció la necesidad de implementar una agenda en la materia que permitiera regular la tala clandestina, considerada como el mayor impacto en el deterioro de recursos forestales. Se propuso un esquema turístico sustentable (aprovechando el potencial natural de la zona) y el apoyo de actores privados para intentar solucionar ciertas deficiencias: falta de infraestructura turística, inexistencia sobre regulación y control de prestadores de servicios turísticos, así como la excesiva concentración de visitantes.

No obstante, pese a los esfuerzos por impulsar la protección de los recursos naturales y la actividad turística, su éxito estuvo limitado por la falta de comunicación y la dificultad de canalizar fondos económicos, ante lo cual, actores privados de carácter internacional ${ }^{6}$ ofrecieron apoyo técnico y financiero con fines de investigación; sin embargo, su participación fue periférica. Por otra parte, la wwF-Programa México se comprometió a realizar un monitoreo de la cobertura forestal del santuario. Asimismo, otros actores sociales como Cruz y Habitat Protection Project plantearon compartir áreas prioritarias para la reforestación. A su vez, Bosque Modelo Mariposa Monarca se comprometió a proporcionar acceso a sus resultados y a las fuentes de financiamiento de proyectos (Toone y Hanscom, 2003: 14-20).

Por lo tanto, la política ambiental en el Santuario El Rosario se caracterizó por la segmentación de sus problemas: deterioro ambiental, turismo masivo, pobreza, entre otros. Con ello, el gobierno federal pretendía dar una atención más específica, aunque sólo generó la presencia de actores que se enlazaron, pero sin cohesión, siendo predominante el propio gobierno federal. Pese a lo anterior, en años siguientes se notó un cambio en la gestión de la política ambiental, siendo su propósito la continuidad de las estrategias planteadas anteriormente aunque sin dejar atrás la segmentación de problemas, dando origen a una política que, como establece Lindblom en Aguilar (1992), se hace y rehace sin cesar.

${ }^{6}$ Los actores privados que participaron fueron: Monarch Watch, Parks Canada, Species at Risk y Monarch Butterfly Sanctuary Foundation (MBSF). 
Es necesario mencionar que no existió un cambio en la administración pública municipal y del estado -ambos del mismo partido político-, lo que permitió no sólo dar continuidad a las acciones y metas planteadas, sino también al flujo de recursos económicos y normativos, así como a la persistencia de la participación de los actores públicos centrales.

En este contexto, bajo la perspectiva de hacer y rehacer la política, el gobierno federal acordó la reestructuración de las acciones en materia ambiental y turística implementadas en el santuario, dando continuidad a las estrategias de inspección, vigilancia del bosque, turismo y proyectos productivos de investigación. Sin embargo, se fusionaron las estrategias de inventario forestal con ordenamiento ecológico y se omitieron la educación ambiental y la coordinación internacional. Esto ayudó a delimitar y evitar el cruce en la jurisdicción de actores públicos y sociales, pero evidenció aún la falta de visión a largo plazo, la escasa capacitación de los recursos humanos y el insuficiente presupuesto para la realización de las acciones.

Como parte de las estrategias que prosperaron en materia turística, hubo un avance de 95\% en el proyecto Parque Temático Mariposa Monarca Ejido El Rosario, ${ }^{7}$ cuya inversión inicial fue de 1,635,382 pesos e incluyó la delimitación de áreas (sanitarios, estacionamiento y locales); asimismo, se impartieron cursos de capacitación a 83 de los 161 ejidatarios propietarios.

Contrario al panorama que hasta ese momento se idealizaba en materia de conservación y protección de los recursos naturales y su aprovechamiento turístico, en el 2006 el gobierno federal, mediante la Semarnat, reconoció la ineficiencia de las acciones de inspección y vigilancia del bosque, una vez que la Alianza wwF-Telcel -actores social y privado, respectivamente, ambos centrales-, anunciaran que el monitoreo anual del bosque (realizado desde el 2003) reflejó una situación preocupante por la pérdida y destrucción de la cubierta forestal. Dado que la tala ilegal generó un grave impacto en la zona núcleo del santuario, esta situación obligó una vez más a reorientar, con base en los mismos objetivos, la política ambiental, hacia actividades alternativas que permitieran el desarrollo social y económico de los pobladores de la región.

En apoyo a esta decisión, el entonces embajador de Estados Unidos en México anunció una inversión de 163 mil pesos para incentivar actividades relacionadas con el turismo, al tiempo que el santuario fue incluido

${ }^{7}$ Los actores públicos que participaron fueron: la Comisión Forestal del Estado y la Coordinación de Relaciones Interinstitucionales; a nivel estatal participó la Coordinación de Comunicaciones y Obras Públicas de Michoacán; en materia social: Biocenosis Región Monarca A.c, representantes de la Escuela Superior de Turismo del Politécnico Nacional, de la Rвмм y del comisariado de los ejidos del municipio de Ocampo. 
en el Fondo para la Conservación de la Mariposa Monarca con la finalidad de obtener recursos que permitieran conservar sus bosques y fortalecer las actividades ecoturísticas en la zona.

En consecuencia, la actividad turística fue concebida como un instrumento de la política ambiental para evitar el deterioro de los recursos naturales y propiciar el desarrollo de la comunidad. Pese a ello, ante la necesidad de los ejidatarios por satisfacer sus necesidades durante la época en que no hay presencia de la mariposa monarca, buscaron fuentes de empleo alternas y en algunos casos emigraron hacia otros países o estados dejando de lado el interés por el turismo y por la conservación del recurso. En tal sentido fue necesaria la creación de mecanismos tendientes a regular esta actividad en el santuario, por lo que en el 2007 fue creada la Dirección de Turismo en el municipio de Ocampo. Su propósito fue establecer lazos de comunicación entre prestadores de servicios, ejidatarios propietarios y miembros de la comunidad, además de consolidar al santuario como un Modelo de Desarrollo Sustentable. ${ }^{8}$

En respuesta a la compleja y, en algunos casos, fallida serie de acciones, y al amplio entramado de organizaciones que interactuaron a lo largo de los años en el santuario con fines de conservación y aprovechamiento turístico, así como a la exclusión constante y permanente de ejidatarios en la toma de decisiones, en el 2009 los 261 ejidatarios propietarios -algunos representados por familiares- realizaron una fuerte movilización, impidiendo el paso de automóviles y peatones al camino que lleva al santuario, lo que dio pauta a un proceso de empoderamiento de El Rosario, marcando así límites en la injerencia de las instituciones oficiales quienes en ese momento no se atrevieron a contrariar la postura del ejido (Serrano y Sánchez, 2008).

Por lo tanto, a partir de 2009 y hasta 2011, los ejidatarios propietarios -actores centrales- de El Rosario se organizaron en tres grupos de 87 personas cada uno. Los grupos se habían encargado de la atención y administración del centro ecoturístico una temporada a la vez. Los 87 participantes recibían en el 2011 un sueldo aproximado de 700 pesos semanales por la actividad asignada. Las ganancias se distribuían entre los 261 ejidatarios titulares, restando los gastos correspondientes al mantenimiento del santuario, actividades de reforestación y vigilancia, así como de abastecimiento de la tienda de alimentos y artesanías, y el mantenimiento de senderos, baños y locales comerciales, según información

\footnotetext{
${ }^{8}$ Esta decisión fue resultado de un acuerdo entre actores públicos estatales y municipales, entre los que destacan: la Secretaría de Turismo, por medio del departamento de turismo alternativo, y el de Ecoturismo, la Secretaría de Educación, la Secretaría de Desarrollo Social; a nivel municipal participó el Ayuntamiento de Ocampo y su Dirección de Turismo. Los actores sociales se integraron por el comisariado del Ejido Cerro Prieto y del municipio de Ocampo, el responsable de la biblioteca del cidem y el ciudadano Héctor García, Ramiro Jerónimo García, ejidatario de El Asoladero.
} 
proporcionada en entrevistas realizadas a ejidatarios en 2010. Adicionalmente, acordaron que, quienes por razones de salud o de trabajo se vieran imposibilitados de participar en la administración del santuario, podrían ser representados por sus hijos o algún miembro de la familia para fungir como guías o, bien, para vender artesanías y comida.

El proceso de rendición de cuentas y la toma de decisiones en torno al santuario se ha realizado mediante la elaboración de asambleas mensuales donde, además de llevar a cabo el conteo del boletaje (éste se compara con el libro de registro de turistas), también se realiza un consenso grupal sobre las necesidades a cubrir en El Rosario. Las asambleas, de acuerdo con las versiones de los ejidatarios, son aprovechadas para organizar faenas de limpieza, brigadas de patrullaje y someter a votación la aceptación de apoyos económicos de organizaciones no gubernamentales que realizan estudios técnicos de prefactibilidad y factibilidad, monitoreo, conservación y manejo de los recursos naturales, y programas de desarrollo comunitario y micro regional.

Pese a la postura en contra de la política ambiental, los ejidatarios acordaron que el gobierno federal, por medio de la Conanp, implementara proyectos productivos alternativos como el taller de costura y serigrafía, lo que más tarde generó conflictos entre ellos. En principio, las personas que recibieron la capacitación para operar los talleres no lo hicieron debido a que en algunos casos emigraron a otros países o estados, o bien, simplemente porque se emplearon en otro tipo de actividad económica. Otro fue el caso de ejidatarios que no respetaron el precio acordado para la venta de las prendas elaboradas y, con ánimo de obtener más ganancias, establecieron un precio diferente al que se acordó en la asamblea. Con ello se generó un proceso interno de competencia desleal. Durante la última temporada de mariposa monarca, el taller se vio obligado a cerrar debido a la falta de materia prima para echarlo a andar.

El manejo de la actividad turística y el cuidado de los recursos naturales en el Santuario El Rosario han tenido un alto grado de autogestión por parte de los ejidatarios, puesto que las acciones que actualmente se llevan a cabo están enfocadas hacia el desarrollo de competencias de los habitantes y prestadores de servicios turísticos locales (ejidatarios propietarios). No obstante, esto ha sido producto de una constante reorientación de la política ambiental y de una amplia participación de actores públicos, sociales y privados (figura II). Si bien, esta situación provocó duplicidad, inacción y omisión de funciones, también generó mejoras en la coordinación interinstitucional nacional e internacional, facilitando en algunos casos el flujo de recursos hacia El Rosario. 


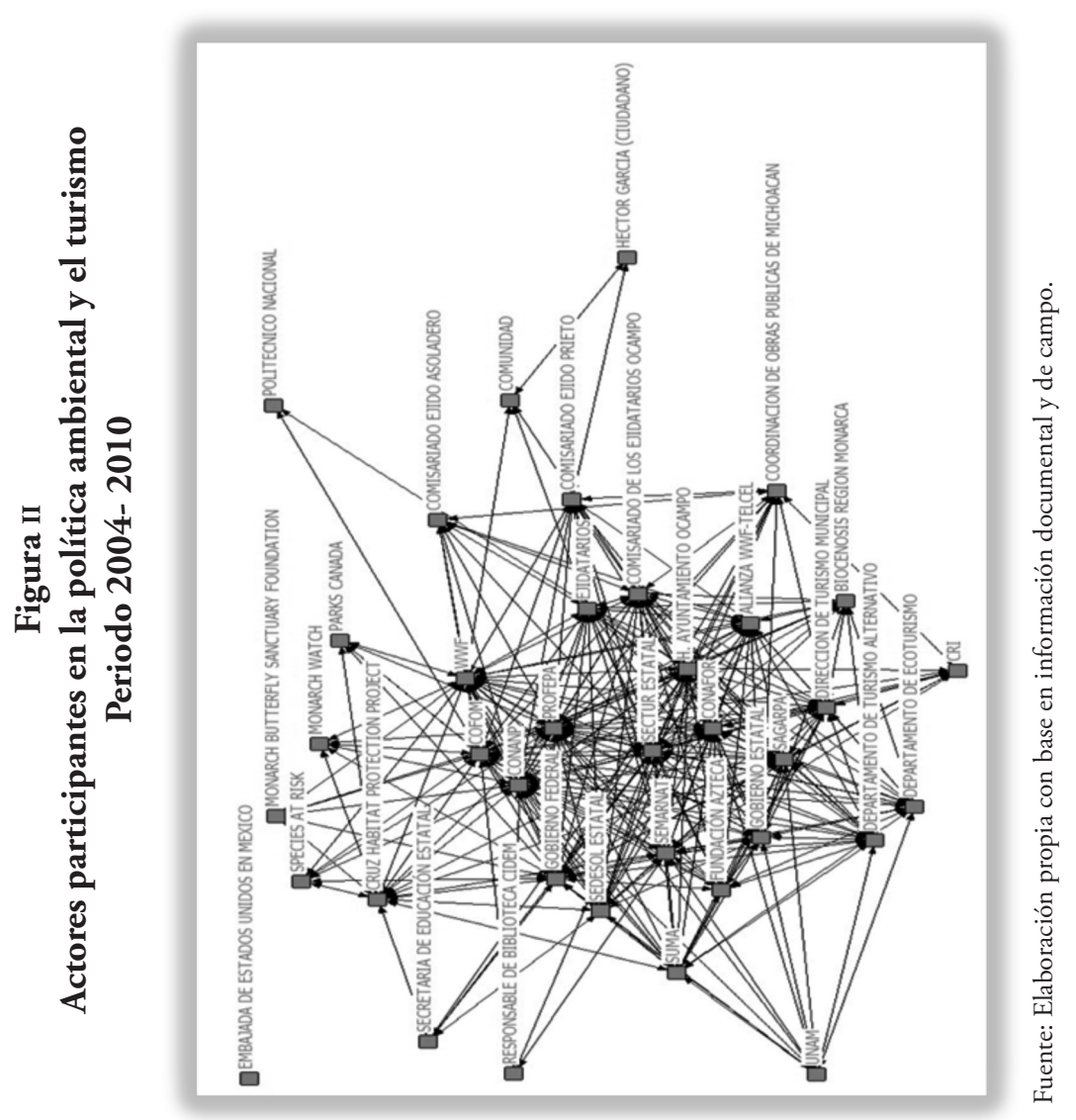




\section{Conclusiones}

La presente colaboración observó desafíos en lo teórico y lo empírico. Respecto a lo primero, los argumentos teóricos sobre redes de política pública que dieron soporte a la investigación posibilitaron abordar al Santuario El Rosario, analizando el complejo entramado de relaciones entre actores de los sectores público, social y privado. Sin embargo, al mismo tiempo, tales relaciones que sustentan el enfoque de redes de política pública, constituyen en lo general un reto metodológico por varias razones: el restringido material sobre casos empíricos referentes a esa perspectiva y sobre el contexto que rige las investigaciones de este tipo; y el riesgo de interpretaciones erróneas y, por consecuencia, distorsionadas respecto al hecho que se aborda, ante la dificultad de analizar relaciones entre actores, sin dejar a un lado el margen de subjetividad que ello implica.

En lo correspondiente a la arista empírica, se reconoce que las medidas de conservación y de aprovechamiento turístico en la RMBB, y en particular en el santuario, han sido insuficientes, puesto que la limitada comunicación interinstitucional entre los ámbitos federal, estatal y municipal ha dificultado el flujo de la información, impidiendo la participación de aquellas organizaciones que contaban con los recursos necesarios para no sólo hacer valer el decreto e implementar dichas estrategias, sino para segmentar los problemas del santuario a fin de resolverlos en conjunto con la comunidad.

Por tanto, la conservación y protección del Santuario de la Mariposa Monarca se constituye como un bien público, y pese a los esfuerzos realizados para implementar proyectos sustentables como el turismo, todavía es necesario incentivar una vinculación democrática y equilibrada de la sociedad civil, así como de la iniciativa privada. Asimismo, se requieren mecanismos de coordinación interinstitucional con un marco regulatorio claro que reúna a las diferentes instancias de gobierno relacionadas con las actividades realizadas en el santuario, a fin de planificar, asignar recursos económicos, dar seguimiento y evaluar resultados.

Por otra parte, es necesaria una estrategia de comunicación, educación, conciencia pública e información crítica y dinámica orientada a todos los actores que participan en El Rosario para propiciar análisis y discusiones permanentes. Esto dará lugar a una sociedad más participativa y, a su vez, permitirá un mejor aprovechamiento de los recursos, así como un manejo, operación y evaluación continua del funcionamiento del santuario. 


\section{Bibliografía}

Aguilar, Luis (1992), La hechura de las politicas, Porrúa, México.

Aguilar, Luis (1996), "Estudio introductorio", en Aguilar Villanueva, L. (ed.) Problemas públicos y agenda de gobierno, Porrúa, México.

Aguilar, Luis (2007), La dimensión administrativa de la nueva gobernanza: sus prácticas y aporte, Porrúa, México.

Alonso, Javier (1994), "Estudio de la vegetación que comprende el hábitat de invernación de Dannaus plexippus L. (Mariposa Monarca) en la Reserva especial de la Biosfera Mariposa Monarca", tesis de licenciatura, eNEP Iztacala-UnAM, México, pp. 125-189.

Brenner, Ludger (2009), "Aceptación de políticas de conservación ambiental: El caso de la Reserva de la Biósfera Mariposa Monarca”, Economía, Sociedad y Territorio, IX (30), El Colegio Mexiquense, A.C., México, pp. 259-295.

Brenner, Ludger y Hubert Job (2012), "Challenges to actor-oriented environmental governance: examples from three mexican Biosphere Reserves", Tijdschrift voor economische en sociale geografie, 103 (1), Royal Dutch Geographical Society, Oxford, pp. 1-19.

Cruz, Graciela (2008), "El turismo como elemento de conflicto y acuerdo en las redes de política pública de Ixtapan de la Sal, México", tesis doctoral, El Colegio Mexiquense A. C., Zinacantepec.

Cruz, Graciela, Rocío del Carmen Serrano Barquín, Carolina Mejía Madero, Luis Eduardo Mejía Pedrero, Juan Magdaleno RezaMeza (2010), "Turismo y sustentabilidad; la complejidad del proceso decisorio en San Miguel Almaya", Revista Ra Ximhai, 6 (3), Universidad Autónoma Indígena de México, Mochicahui, El Fuerte, pp. 379-392.

Dof (Diario Oficial de la Federación) (2000), "Decreto ampliación de la Reserva de la Biosfera de la Mariposa Monarca”, 10 de noviembre, México. 
Dof (Diario Oficial de la Federación) (2000), "Programa de manejo del Santuario de la Mariposa Monarca El Rosario", 30 de noviembre, México.

El Sol de Morelia (2008), "Mariposa Monarca, una especie en extinción" 9 de Julio, México, p. E5.

Esquivel-Ríos, Susana, Graciela Cruz Jiménez, Lilia Zizumbo Villareal, Cecilia Cadena Inostroza, Rocío del Carmen Serrano Barquín (2011), "Turismo rural, política ambiental y redes de política pública en la Reserva de la Biosfera de la Mariposa Monarca”, Rosa dos Ventos, 3 (2), Universidad de Caxias do Sul, Caxias do Sul.

FARN (Fundación Ambiente y Recursos Naturales) (2009), Informe anual ambiental 2009, <http://www.farn.org.ar/>, 3 de diciembre de 2009.

Foladori, Guillermo (2002), "Avances y límites de la sustentabilidad social”, Economía, Sociedad y Territorio, III (12), El Colegio Mexiquense, A.c., Zinacantepec, pp. 74-96.

García, E. (1981), Modificaciones al sistema de clasificación climática de Köppen, Instituto de Geografía, unam, México.

INE (Instituto Nacional de Ecología) (1987), "Reserva especial de la biosfera mariposa monarca”, Instituto Nacional de Ecología, México.

Instituto Nacional de Estadística, Geografía e Informatica (INEGI) (1981), “Carta Topográfica”, Instituto Nacional de Estadística, Geografía e Informática, Aguascalientes.

Juan y Seva, Grisselle (2005), Ensayo: turismo y sustentabilidad, Universidad Autónoma del Estado de México, México.

Klijn, Erik Hans (1998), "Redes de política pública. Una visión general”, en W.J.M. Kickert y J.F. Koppenjan (eds.), Managing Complex Networks, Sage, London, http://revista-redes.rediris.es, Wwebredes/textos/Complex.pdf, 18 de octubre de 2009.

La Voz de Michoacán (1993), "Comunidad Indígena y Mariposa Monarca” 2 de junio de 1992 y 8 de mayo de 1993, México, p. 6. 
Loredo, Olga (2000), "Aprovechamiento de los recursos bióticos en el ejido El Rosario, estado de Michoacán”, tesis de licenciatura, Facultad de Ciencias-unam, México.

Lowi, Theodore (2000), "Políticas públicas, estudios de caso y teoría política", en Luis Aguilar Villanueva, La hechura de las políticas públicas, Porrúa, México, pp. 25-32.

Orduña, T.C. y P. Salas (1987), "Diversidad avifaunística y mastozoológica en la región Centro-Norte del estado de Michoacán”, en Libro de resúmenes del V Simposio sobre Fauna Silvestre, Facultad de Medicina Veterinaria y Zootecnia-unam, México.

Porras, Ignacio (2001), "Policía Network o red de políticas públicas: Una introducción a la metodología de investigación", Estudios Sociológicos, XIx (57), El Colegio de México, http://codex.colmex.mx, 29 de noviembre del 2009.

Programa de la Rвмm (2001), citado en Susana Esquivel-Ríos, Graciela Cruz-Jiménez, Lilia Zizumbo-Villareal, Cecilia Cadena-Inostroza y Rocío del Carmen Serrano-Barquín, "Turismo rural, política ambiental y redes de política pública en la Reserva de la Biosfera de la Mariposa Monarca", Rosa dos Ventos, 3 (2), Universidad de Caxias do Sul, Caxias do Sul.

Quintero, Genoveva (2007), "Políticas públicas y el medio ambiente", Tecnología en Marcha, 21 (1), Ed. Tecnología de Costa Rica, Costa Rica, pp. 141-151.

Rendón-Pérez, Eduardo, Alicia Jazmín Ibarra y Carlos Galindo (eds.) (2005), "Antecedentes Mariposa Monarca", Memorias (Segundo Foro Regional Mariposa Monarca. Memorias), Casa de Gobierno, Morelia, pp. 1-48.

RENPA (2011), "Otros ámbitos de protección. Reservas de la Biosfera", Junta de Andalucía, Consejería de Medio Ambiente y Ordenación del Territorio, México. pp. 1-12.

Rosas, Angélica (2008), "Una ruta metodológica para evaluar la capacidad institucional", Política y Cultura, Uam unidad Xochimilco, núm. 30, México, pp. 119-134. 
SARH (Secretaría de Agrícultura y Recursos Hidráulicos) (1992), "Propuesta para la zonificación y clasificación de los terrenos forestales y del área de influencia del área de la Reserva especial de la Biosfera de la Mariposa Monarca", Secretaría de Agricultura y Recursos Hidráulicos, México.

Scharpf, Fritz (1978), "Interorganizational policy studies: issues, concepts and perspectives" en K.I. Hanf y Fritz Scharpf (eds.), Interorganizational policy making. See Hanf and Scharpf, Westview Press, Boulder, Germany, pp. 345-70.

Serrano, María y Juan Sánchez (2008), "Entre el pasado, el presente y la construcción de futuro del desarrollo rural. Percepciones y expresiones desde las experiencias campesinas", Coloquio Ibérico de Estudios Rurales, 23-25 de octubre, Coimbra.

Servicio Geológico Mexicano (2000), "Carta Geológica-Minera Angangueo E14-A26, Mich.-Edomex., Esc. 1:50,000”, Servicio Geológico Mexicano, Pachuca, México.

Subirats, Joan (2008), Análisis y gestión de políticas públicas, Ariel, México.

Toone, William y Thomas Hanscom (2003), "Conservation of monarch butterflies in Central Mexico: Protection of a biological phenomenon", Biodiversity, 4, Oxford Journals, Oxford, pp. 89-93.

Vásquez, Miguel (2007), "Políticas públicas ambientales. Una reflexión", Las politicas públicas y los compromisos de la investigación, División de Conservación de la Biodiversidad de Ecosur-Instituto Nacional de Ecología, México, pp. 13-16.

Recibido: 16 de diciembre de 2011.

Reenviado: 15 de marzo de 2013. Aceptado: 19 de agosto de 2013.

Susana Esquivel-Ríos. Es maestra en estudios turísticos y especialista en docencia turística por la Universidad Autónoma del Estado de México. Actualmente es doctorante en estudios turísticos por la Facultad de Turismo y Gastronomía de la UAEM. Obtuvo la presea Dr. Gustavo Baz Prada Cemapem 2007 por la investigación "Condiciones para la incorporación de proyectos ecoturísticos en el municipio de Jilotzingo, Estado 
de México". Entre sus últimas publicaciones destacan: en coautoría, "Turismo rural, política ambiental y redes de política pública en la Reserva de la Biosfera de la Mariposa Monarca", Rosa dos Ventos, Universidade de Caxias do Sul, 3 (2), pp. 290-300 (2011); "Política ambiental y sustentabilidad en el diseño de proyectos turísticos en el Santuario de la Mariposa Monarca El Rosario", Coloquio Internacional de Diseño, 23 y 24 de septiembre de 2010, Toluca, México.

Graciela Cruz-Jiménez. Es doctora en ciencias sociales por El Colegio Mexiquense, A.C. Actualmente es profesora-investigadora de la Facultad de Turismo y Gastronomía de la Universidad Autónoma del Estado de México. Es miembro del Sistema Nacional de Investigadores. Su línea de investigación actual es turismo, sustentabilidad y desarrollo local. Es directora editorial de la revista El Periplo Sustentable. Entre sus últimas publicaciones destacan, en coautoría: "Red de política pública. Estructura y funcionamiento en un proceso de sensibilización. San Miguel Almaya, México", Revista de Antropología Experimental, núm. 13, Universidad de Jaén, España, pp. 113-127 (2013); "La transición de una comunidad agrícola a turística: Ixtapan de la Sal”, Rosa dos Ventos, 4 (2), Universidade de Caxias do Sul, Caxias do Sul, pp. 1-13 (2012); en coautoría: "Capacidades colectivas y redes de políticas públicas: enfoques teórico-metodológicos en la conformación de políticas turísticas en San Mateo Capulhuac, México", Vectores de investigación, 4 (14), Centro de Investigación de Estudios Comparados de América Latina, Toluca, pp. 91-102 (2012).

Cecilia Cadena-Inostroza. Es doctora en ciencias políticas y sociología por la Universidad Complutense de Madrid. Actualmente es profesorainvestigadora de El Colegio Mexiquense, A.C. Es miembro del Sistema Nacional de Investigadores nivel I. Líneas de investigación: políticas públicas y gestión municipal, redes de política pública, transparencia y rendición de cuentas en gobiernos municipales. Entre sus últimas publicaciones destacan: "Instituciones que no han ayudado al desarrollo. El acceso a la información en municipios del Estado de México", en Ady Carrera (coord.), Instituciones y Desarrollo (en prensa); en coautoría: Estado de México. Historia Breve, Fideicomiso para la historia de las Américas, Fondo de Cultura Económica-El Colegio de México, México, 262 pp. (2011); "Agua potable y redes de política pública. Entre la captura y la exclusión. Caso de los comités independientes de agua potable en el municipio de Toluca”, en Francisco J. Porras Sánchez (coord.), Redes de política pública en México, Instituto de Investigaciones José María Luis Mora, México, pp. 197-244 (2011). 
Lilia Zizumbo-Villarreal. Es doctora en sociología por la Universidad Nacional Autónoma de México. Actualmente es profesora-investigadora de la Facultad de Turismo y Gastronomía de la Universidad Autónoma del Estado de México. Es miembro del Sistema Nacional de Investigadores, nivel II. Su línea de investigación actual es estudios ambientales del turismo. Entre sus últimas publicaciones destacan: Las paradojas del desarrollo local y del turismo, Universidad Autónoma del Estado de MéxicoPorrúa, 250 pp. (2013); en coautoría: Contra la domesticación del turismo. Los laberintos del turismo rural, Universidad Autónoma del Estado de México-Porrúa, Toluca, 258 pp. (2010); en coautoría: "Las Bogot de dominación capitalista en el espacio rural: La configuración de paisajes turísticos", Cuadernos de Desarrollo Rural, 9 (69), Pontificia Universidad Javeriana, Bogotá, pp. 151-174 (2012); 'La confrontación social por el espacio costero. La configuración de paisajes turísticos en puerto Morelos, Quintana Roo, México", Región y Sociedad. Revista del Colegio de Sonora, XXV (56), El Colegio de Sonora, Hermosillo, pp. 127-160 (2013); 'La transformación de los espacios de vida a partir del turismo en puerto Morelos, Quintana Roo, México", en Polis Revista Latinoamericana, 12 (34), Universidad de los Lagos-cispo, Santiago, pp. 307-332 (2013). 